\title{
Geriatric Basics for the Neurohospitalist
}

The Neurohospitalist

2018, Vol. 8(2) 92-10

(C) The Author(s) 2017

Reprints and permission:

sagepub.com/journalsPermissions.nav

DOI: $10.1177 / 1941874417738697$

journals.sagepub.com/home/ $\mathrm{NHO}$

(S)AGE

\author{
Josef G. Heckmann, MD, PhD', Jörg Kraus, MD, $P h D^{2,3}$, \\ and Christoph J. G. Lang, MD, $\mathrm{PhD}^{4}$
}

\begin{abstract}
Due to the increasing age of the population, neurohospitalists are more frequently caring for old and very old people. Fundamental definitions and topics related to geriatric medicine are therefore of particular importance. In this review, common issues encountered in geriatric patients hospitalized on the neurology service are discussed. Focus is put on the geriatric assessment, multiprofessional diagnostic and therapeutic procedures, geriatric syndromes, pharmacotherapy of the aged, delirium, pain, and palliative management as they are relevant for the neurohospitalist. In addition, ethical questions are addressed.
\end{abstract}

\section{Keywords}

geriatrics, neurogeriatrics, elderly patients, rehabilitation, aging

\section{Introduction}

Human life expectancy has dramatically improved within the last century, both in industrialized and developing countries. Currently, the mean life span is 82 years for women and 78 years for men in Europe. Very old persons aged over 80 years make up the most rapidly increasing population group. The number of centenarians is also markedly rising. ${ }^{1}$ The age structure in industrialized countries is therefore no longer to be described as an age pyramid but rather as an age urn. However, with increasing age, numerous strongly agerelated diseases and risk factors with gender-specific features occur more frequently such as arterial hypertension, diabetes, atrial fibrillation, cancer, and neurodegenerative diseases. $^{2}$

With an increasing life span, the future trend in morbidity of older persons is currently not foreseeable. One possible scenario is an increase in morbidity among people with advanced age leading to an extension of morbidity, which means that humans will live longer but with more sickness and disability. ${ }^{3}$ Thus, in the near future, we may enter a new era of increasing prevalence of cardiovascular disease, cancer, and neurodegenerative disease. ${ }^{4}$

These demographic changes are accompanied by a number of questions on organization and concepts of health care as well as social economics. With respect to distribution of resources in hospitals, geriatric medicine will become more and more important. Thus, almost all medical disciplines will have to deal with geriatric themes. The aim of this article is to present the basics of geriatric know-how for the neurohospitalist in daily clinical practice.

\section{Epidemiology, Burden of Disease}

From the view of a neurohospitalist, it is important to consider 2 epidemiological aspects when caring for old and very old patients. First, the aspect of multimorbidity; an increase in the number of chronic conditions has to be expected whereby more than 1 of these conditions might occur in 1 person. Multimorbidity leads to an increase in disability, decrease in life quality, higher necessity of professional medical care, and even mortality. Second, most neurological disorders are age-dependent such as stroke, Parkinson disease, dementia, polyneuropathies, and epilepsy. ${ }^{5}$ In this context, the geriatric syndromes (see below) are phenomenologically encapsulated. ${ }^{6}$ They indicate the elevated vulnerability of the patient and restricted resources to overcome acute decompensation or illness.

Recently, the occurrence of multimorbidity ( 3 and more diseases, according to International Classification of Diseases, Tenth Revision, simultaneously in 1 person) was

\footnotetext{
' Department of Neurology, Municipal Hospital Landshut, Landshut, Germany ${ }^{2}$ Department of Neurology, Medical Faculty, University Hospital Düsseldorf, Düsseldorf, Germany

${ }^{3}$ Department of Laboratory Medicine, Paracelsus Medical University, Salzburger Landeskliniken, Salzburg, Austria

${ }^{4}$ Department of Neurology, Medical Faculty, University Hospital Erlangen, Erlangen, Germany

Corresponding Author:

Josef G. Heckmann, Department of Neurology, Municipal Hospital Landshut, Robert-Koch Str. I, 84034 Landshut, Germany.

Email: josef.heckmann@klinikum-landshut.de
} 


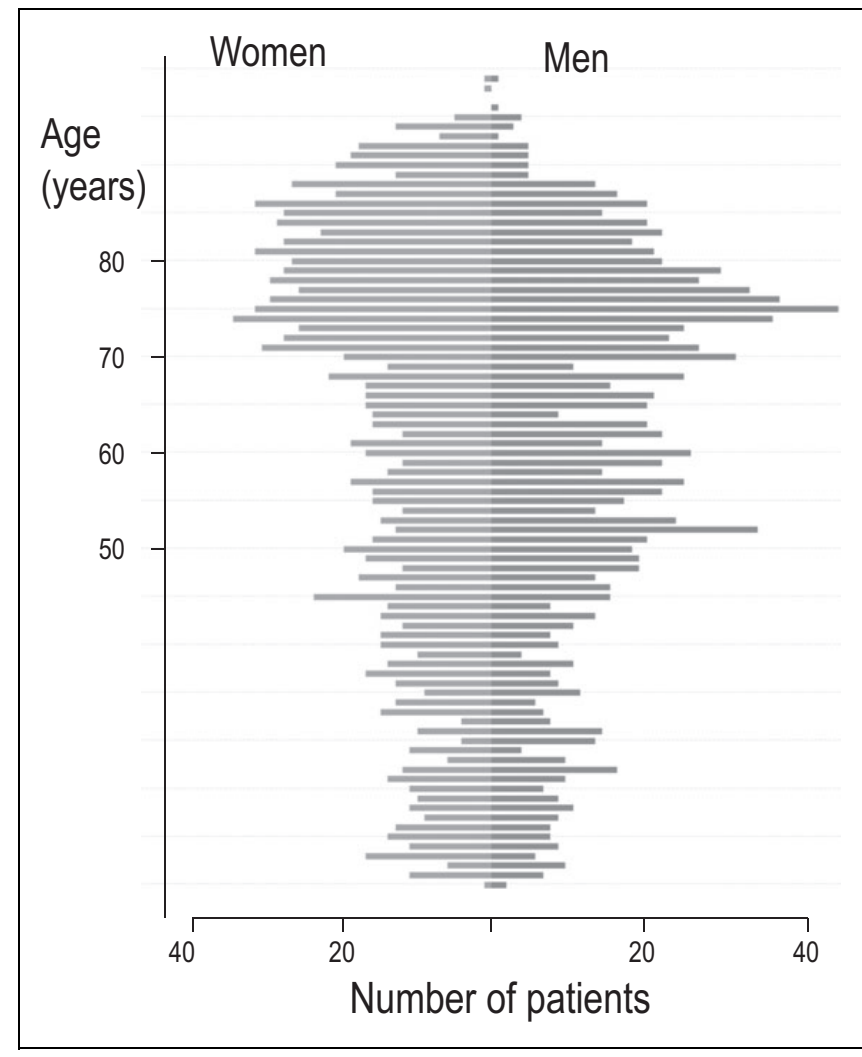

Figure I. Age distribution of neurohospitalized patients in a neurologic department of a secondary care hospital $(n=2672$; year 2015).

evaluated in a German study. More than $60 \%$ of the investigated persons (age $>65$ years) were found to have multimorbidity. Moreover, clusters of disease patterns were identified, such as cardiovascular (hypertension, ischemic heart disease), metabolic (diabetes, dyslipidemia), chronic low-back pain and osteoarthritis, as well as neuropsychiatric syndromes (anxiety, depression, somatoform disorder). ${ }^{7}$ Focusing on the epidemiology of neurodegenerative disorders, a further increase can be anticipated. ${ }^{5}$ Even in developing countries, an increase in multimorbidity that includes neurological and mental disorders is clearly recognizable. ${ }^{8}$ It should therefore be reckoned that the care of old and very old people will become increasingly important, both in the ambulatory setting and in the neurohospital field. In a sample of neurohospitalized patients from our hospital, the majority was older than 70 years (Figure 1).

\section{Definitions in Geriatric Medicine}

According to a broadly accepted definition, a geriatric patient is 70 years and older with typical geriatric multimorbidity or older than 80 years with an inevitable age-associated vulnerability that increases the risk of developing geriatric problems. The term "geriatric syndrome" describes a group of signs and symptoms that occur in parallel and do not represent a defined disease category. ${ }^{6}$ The syndromes delirium, falls, frailty, loss
Table I. Geriatric Syndromes (“Giants" or "I”s) and Its Definitions.

Geriatric

Syndromes

(giants or "l"s) Associated Challenges

Instability Falls, inactivity, inanition, dizziness, syncope

Immobility Sarcopenia, frailty, pressure ulcers

Intellectual decline Mild cognitive impairment, dementia, confusion, delirium

Incontinence Urge-, overflow- or stress-incontinence, obstruction of voiding, impaired storage, constipation

Isolation Social deprivation, insolvency, poverty, poor housing, self-neglect

Inappetence Fluid intake disorder, malnutrition, impaired homeostasis, weight loss

Interest loss Depression, anxiety

latrogenesis

Polypharmacy, inappropriate prescribing, pharmacological prescribing cascade, adverse drug effects, complex drug history

of consciousness, and incontinence have to be seen in this context. In order to memorize the main geriatric syndromes easier, the geriatric "I"s or geriatric giants have been proposed: instability, immobility, intellectual decline, incontinence. At this point, "isolation" (social loneliness) and "inappetence" may be added. The latter one refers to malnutrition and fluid intake disorder of elderly patients. Loss of interest in the context of depression may be a further geriatric syndrome, not to forget "iatrogenic" disturbances and frailty (Table 1). ${ }^{9}$

In the diagnostic and therapeutic process, geriatrics play a determining role. It leaves the way of thinking within organrelated pathology and focuses instead on functionality, which is strongly related to independence, autonomy, and participation in family and society. Preventive, curative, rehabilitative, and palliative treatment modules are combined in order to achieve these goals in the geriatric therapeutic process. Organ-related medicine typically focuses on guidelines of different medical societies. In the case of complex multimorbidity, as is the rule in geriatric patients, guidelines cannot be applied singly. In contrast to organ-related medicine, it is usually necessary to prioritize diagnostic and therapeutic measurements in order to achieve the aim of functionality and autonomy. For daily clinical work, it is therefore imperative to perform a geriatric basic or comprehensive assessment after history taking and clinical examination. ${ }^{10}$ Different forms of geriatric assessment have been proven to significantly improve outcome in caring for older people. ${ }^{11}$

\section{Geriatric Assessment and Therapeutic Process}

The aim of the geriatric assessment is to identify functional deficits and particularly resources of the elderly patient using 
Table 2. Most Frequently Used Geriatric Assessment Instruments (Modified According to Blundell and Gordon). ${ }^{12}$

\begin{tabular}{|c|c|}
\hline Domain & Tests \\
\hline Independence & Barthel Index, IADL \\
\hline Cognition & $\begin{array}{l}\text { MMSE, Clock-Drawing Test, DemTect, Money } \\
\text { counting test according to Nikolaus }{ }^{\text {a }}\end{array}$ \\
\hline Mood, depression & $\begin{array}{l}\text { Geriatric Depression Scale, Erlangen } \\
\text { Depression Scale }\end{array}$ \\
\hline Malnutrition & Mininutrial Assessment, meal and drink protocol \\
\hline Mobility & $\begin{array}{l}\text { Time up and go test, Tinetti test, modified } \\
\text { Romberg, analysis of walking velocity, 5-chair } \\
\text { raise test, Demmy test, short physical } \\
\text { performance test battery, Berg balance test }\end{array}$ \\
\hline Social participation & Social questionnaire according to Nikolaus ${ }^{\mathrm{b}}$ \\
\hline Pain & $\begin{array}{l}\text { Visual, numeric, and verbal pain scales, } \\
\text { PAINAD, }{ }^{c} \text { DOLOplus }{ }^{d}\end{array}$ \\
\hline
\end{tabular}

Abbreviations: IADL, instrumental activities of daily living; MMSE, Mini-Mental State Examination.

${ }^{a}$ Money counting test according to Nikolaus. ${ }^{76}$

bocial questionnaire according to Nikolaus. ${ }^{77}$

'PAINAD, Psychometric Evaluation of the Pain Assessment in Advanced

Dementia. $^{78}$

${ }^{\text {DOLOplus. }}{ }^{79}$

a holistic approach. The applied instruments are the manifold tools of the geriatric assessment, which is in a certain way the "stethoscope" of the geriatrician (Cornel Sieber, personal communication, march 2016). These assessment methods are well validated and highly reliable. ${ }^{12}$ In Table 2 , the most frequently used geriatric assessment tools are summarized (Table 2).

Not every elderly patient needs a geriatric assessment. A screening of the patient to determine whether he or she shows geriatric features is therefore reasonable. The screening according to Lachs is widely used and consists of a protocol that considers 15 items of daily life and function. ${ }^{13}$ It enables the user to identify geriatric problems that need further diagnostic and therapeutic procedures. Another screening tool is the geriatric screening at hospital entry as recommended by the working group of geriatricians in Bavaria. ${ }^{14}$ In this protocol, age, reduced mobility, necessity of home care, and typical geriatric multimorbidity are verified. If 2 or more "yes" answers are present, a specific geriatric assessment is advised. The screening method "Identification of Seniors At Risk" is another broadly accepted scale applied for geriatric patients in the emergency department. ${ }^{15}$

The geriatric diagnostic and therapeutic process can be divided into 6 steps (Figure 2). ${ }^{16}$ In the first step, after history taking and clinical examination, it is necessary to deliver acute specific treatments as indicated in the context of index symptoms such as dyspnea, chest pain, stroke, or fracture. In the second step, the geriatric assessment (see above) is performed, with the aim of evaluating the patient's own resources that can be used and supported by an individualized therapeutic process. The third step refers to communication within the

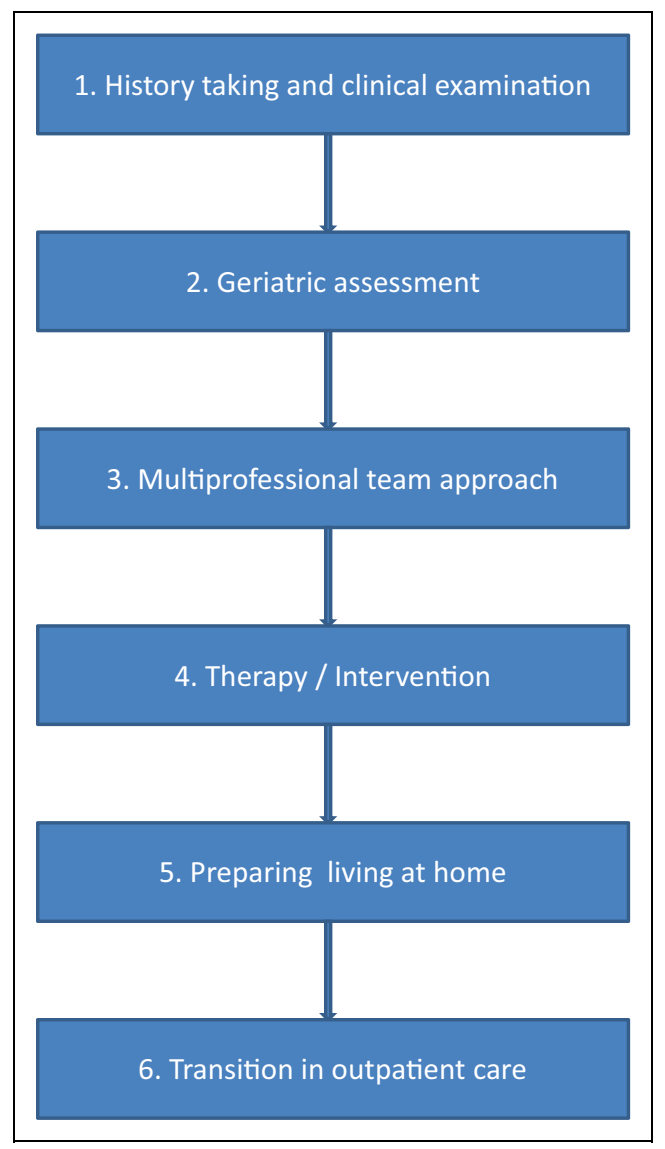

Figure 2. Scheme of geriatric diagnostic and therapy process.

multiprofessional team and formulation of the treatment aims. The fourth step is the most important and involves the therapeutic intervention with weekly team conferences to discuss the potential of optimizing medical and nonmedical procedures. The fifth step focuses on discharge with optional home visits by occupational therapists or nurses, medical stress holidays, and medical aid supply. Finally, in the sixth step, the patient's transition into outpatient care is organized including food and household supply, in-house emergency call, and instruction of family member carers. Such a bridging strategy will markedly improve patient safety across the continuum of care. ${ }^{17}$

Specific geriatric early rehabilitation is a concept that was developed to enable multidimensional treatment of elderly patients with complex diseases. This concept comprises at least 20 therapy units for at least 14 days by a multiprofessional team. ${ }^{18,19}$ Specific geriatric early rehabilitation aims to preserve independence and to diminish the need for nursing care in elderly patients. Despite well-developed structures, a continuous improvement process needs to be sustained in order to activate the hidden potentials of elderly patients. ${ }^{20}$

\section{Pharmacotherapy of Elderly Patients}

Geriatric patients frequently are treated with numerous drugs due to various diseases. However, adverse events have the 
potential to induce a prescription cascade. It is estimated that about $10 \%$ of acute hospital admissions are based on treatment-associated adverse events. Dormann and colleagues found that in patients presenting to an emergency department, almost $30 \%$ of elderly patients revealed at least 1 unwanted side effect, and in $40 \%$, a medication error was identified. ${ }^{21}$ For this reason, it is important to regularly check the patient's medications. Projects such as the Optimized Prescription in Old Age or the implementation of a geriatric clinical pharmacist in the therapeutic team may be valuable. ${ }^{22}$ Typical problems of pharmacotherapy are inadequate dosages (too much, too high, too long), insufficient patient information, functional disturbances of the patient (swallowing, parting of tablets, counting of drops, opening of tablet blisters), and neglecting the comedications (eg, cumulative anticholinergic load). This problem has been recognized and the term "potential inadequate medication" was introduced. The use of negative lists such as the Beer's list or the PRISCUS list can be helpful to address this problem. Further alternatives are the assessment criterions for drugs as "Fit fOR The Aged" or the medication appropriateness index criteria. ${ }^{23,24}$

In particular, the question of how many drugs the patient really needs is of great importance. It is imperative to check the indication, to balance risks and benefits, to look for alternative treatment options, and if indicated to titrate the optimal dosage. The recent proposed BEGIN algorithm (considering Basis for therapy, Evaluation of risks, Given agreement, Intention of likely benefit, and No better alternative) may help guide appropriate pharmacotherapy. ${ }^{25}$ Such an approach may lead to a discontinuation and reduction of drugs. ${ }^{26,27}$ Besides multimorbidity and polypharmacotherapy, the functionality of the patient (cognition, mobility, visual capacity, manual skills, and capacities in activities of daily living) and age-related physiological changes such as increase in fat tissue, reduction in muscle and bone tissue as well as free water, and decline in kidney and liver function have to be taken into consideration.

Changes in pharmacokinetics as well as in pharmacodynamics are common in elderly patients. ${ }^{28}$ These changes affect the sensitivity of an organ against a specific drug (Table 3).

Particularly risky drugs in elderly patients are digitalis, theophylline, anticoagulants, antidiabetics, and insulin. They most frequently lead to relevant unwanted side effects. ${ }^{29}$

Drug-drug or drug-disease interactions should also be taken into account. Some are summarized in Table $3 .{ }^{30}$ Many clinical problems caused by pharmacotherapy may arise such as intoxications, confusional states, falls, syncope, electrolyte disorders, liver damage, and gastrointestinal disturbances. Optimization of pharmacotherapy is therefore crucial and the geriatric pharmacological law "start low, go slow" should be followed tightly with adaption of dosages in case of liver and kidney dysfunction and avoidance of anticholinergic drugs if possible. ${ }^{29,31,32}$ Monitoring of drugs, for example, anticoagulant therapy, antidiabetics, digitalis, or antiepileptics, may be helpful. Nonmedical therapy regimens such as physiotherapy, occupational therapy, speech and
Table 3. Common Problems Regarding Age-Related Interactions and Changes in Pharmacokinetics and Dynamics,and Pharmacological Management of Elderly People.

\begin{tabular}{|c|c|}
\hline Problem, Concern & Comment \\
\hline Pharmacokinetics & $\begin{array}{l}\text { Decreased resorption, distribution, } \\
\text { metabolism, and excretion }\end{array}$ \\
\hline Pharmacodynamics & $\begin{array}{l}\text { Changed sensitivity of organs against } \\
\text { drugs. } \\
\text { Brain more sensitive to opioids, } \\
\text { psychotropics; heart less sensitive } \\
\text { to } \beta \text {-blockers }\end{array}$ \\
\hline Diuretics & $\begin{array}{l}\text { Orthostatic hypotension, } \\
\text { hyponatremia }\end{array}$ \\
\hline Anticholinergic load & $\begin{array}{l}\text { Increased risk of falls and delirium by } \\
\text { polypharmacotherapy including } \\
\text { urologic drugs, steroids, NSAID, } \\
\text { psychotropics }\end{array}$ \\
\hline
\end{tabular}

\begin{tabular}{|c|c|}
\hline \multicolumn{2}{|l|}{ Dangerous interactions } \\
\hline SSRI and sulfonyl urea & Increased risk of hypoglycemia \\
\hline SSRI and $\beta$-blockers & $\begin{array}{l}\text { Increased risk of bradycardia and } \\
\text { arterial hypotension }\end{array}$ \\
\hline SSRI and anticoagulants & Increased risk of bleeding \\
\hline $\begin{array}{l}\text { Macrolides and calcium } \\
\text { channel blocker }\end{array}$ & Increased risk of QT-prolongation \\
\hline $\begin{array}{l}\text { Macrolides and } \\
\text { anticoagulants }\end{array}$ & Increased risk of bleeding \\
\hline Competition in protein binding & NSAID and anticoagulants \\
\hline Serotonin syndrome & $\begin{array}{l}\text { Accumulation of serotonergic drugs } \\
\text { like SSRI, tramadol and triptans }\end{array}$ \\
\hline $\begin{array}{l}\text { Competition on COX-I- } \\
\text { inhibition }\end{array}$ & ASS and ibuprofen or naproxen \\
\hline \multicolumn{2}{|l|}{$\begin{array}{l}\text { Changes in the metabolism of } \\
\text { drug degradation (different } \\
\text { cytochrome P450 systems) }\end{array}$} \\
\hline Additive effects & $\begin{array}{l}\text { NSAID and steroids on gastric } \\
\text { mucosa (gastrointestinal bleeding) } \\
\text { and QT time prolongation }\end{array}$ \\
\hline $\begin{array}{l}\text { Thiazide diuretics } \\
\text { PPI }\end{array}$ & $\begin{array}{l}\text { Provocation of gout attacks } \\
\text { Increased risk of clostridium difficile } \\
\text { infection }\end{array}$ \\
\hline
\end{tabular}

Abbreviations: ASS, acetylsalicylic acid; COX-I, cyclooxygenase-I; NSAID, nonsteroidal anti-inflammatory drug; PPI, proton pump inhibitor; SSRI, selective serotonin reuptake inhibitor.

swallowing therapy, physical measurement, and medicinal baths need to be integrated in the holistic therapeutic approach as often as possible.

Despite the fact of widespread polypharmacotherapy, it is also important to mention that some patients are undertreated as they do not receive necessary evidence-based drugs. Both over- and undermedication have to be considered. ${ }^{33}$

\section{Immobility and Falls}

Mobility is of important significance as it greatly influences autonomy, independence, and quality of life. Impaired mobility leads to numerous negative changes such as reduction in muscle and bone mass, reduced joint motility, trophic skin 
changes with the risk of decubital ulcers, diminished blood volume and orthostatic hypotension, and psychological changes such as depression and apathy.

It is of particular relevance to assess the mobility of the patient in the diagnostic process. Well-proven methods are the walking test with estimation of the walking velocities (spontaneous walking, rapid walking), the timed up and go test, the 5 rise chair test (strength of the hip muscles), the modified Romberg test (including semi-tandem and tandem stand), the Tinetti test, and others. ${ }^{34}$ The therapeutic approach is multifaceted with therapy of acute diseases, physical rehabilitation, control of risk factors, as well as prophylaxis of potential complications by arrangement of the living environment, use of walking aids, external support, and psychosocial assistance.

Falls are the most dreaded complications of both impaired mobility and balance disorders. Nearly a third of the persons aged 65 years and older and half of the persons aged 80 years and older fall at least once a year. Nursing home residents fall on average twice every year. Most falls are harmless; however, $10 \%$ of the fallers sustain injuries and $5 \%$ bone fractures where fractures of the radius and of the hip predominate. More than half of the fallers are not able to get up by themselves and are found in a helpless condition often after a long period. This may lead to concomitant complications such as rhabdomyolysis, dehydration, or decubital ulcers. Every fifth person falls repeatedly and an additional almost $20 \%$ develop a specific anxiety to fall again. ${ }^{35,36}$ Inpatient falls are a particular problem needing different risk stratification and prevention tools. ${ }^{37}$ Fractures, in particular of the hip region, are associated with high mortality or the need for nursing care.

It is therefore extremely important to evaluate the underlying cause of a fall. ${ }^{36}$ It needs to be ascertained whether the fall was accompanied by a loss of consciousness, by external circumstances, or whether the etiology was multifactorial (neurological disorders, analgesic problems, impairment of senses, inadequate medication). Mobility and potential risk of falling need to be assessed by specific measurements at the beginning of the diagnostic process. Such measures include muscle strength and balance training supervised by physiotherapists or sports therapists and aim to improve the walking capacity as well as the balance. In particular, Tai Chi, dancing, rhythmic movement, or special programs such as the Ortago program have been proven to be effective. External medical aid supply and measures for secure habitation also contribute to prevent falls. In addition, supplementation of vitamin D significantly reduces the risk of fractures. In individual cases, hip protectors can be applied. ${ }^{34}$ When discussing the patient's medication, pharmacotherapy has to be checked to identify fall risk increasing drugs .

By considering these points, it is estimated that about $30 \%$ to $40 \%$ of falls can be avoided. Beside history taking, clinical examination, assessment of mobility and general geriatric basic assessment, tests of visual capacity, blood pressure regulation (Schellong test), neurological functions (proprioception, movement, coordination), and cardiac functions (silent aortic stenosis) should therefore be performed. Moreover, preventive measures need to be started early in which physical exercises and activities play an important role. The American College of Sports Medicine advises elderly individuals to perform physical activity with getting winded 5 times a week for at least 30 minutes or, alternatively, physical activity with getting sweated 3 times a week for 20 minutes. ${ }^{34}$

\section{Sarcopenia and Frailty}

The term sarcopenia describes the age-related decrease in musculature associated with a loss of muscle function and muscle strength. ${ }^{38}$ Healthy individuals lose about $1 \%$ to $2 \%$ of their muscle mass per year under physiological conditions, beginning at the age of 30 . With advanced age, this reduction is accelerated with marked impact on the walking capacity, risk of falls, ejection fraction of the heart, pulmonary capacity, and glucose metabolism. Inflammation with elevated C-reactive protein, elevated interleukin- $1,-6$ and $-\delta$, elevated tumor necrosis factor (inflammation), and endocrine age-related changes (menopause, andropause, adrenopause, somatopause) are thought to play an etiopathological role. In addition, neuronal alterations are relevant such as decrease in alpha-motoneurons and changes at the neuromuscular junction. ${ }^{38}$ The main problem of sarcopenia is a vicious circle of immobilization that strongly amplifies the process of muscle atrophy.

The transition from sarcopenia to frailty is fluent. Frailty describes a condition of elevated susceptibility to external and internal stressors on the background of age-related diminished physiological and functional reserves. ${ }^{39}$ Frailty may be diagnosed if 3 of the following 5 criteria are present: weight loss (more than $5 \mathrm{~kg}$ in the last year), amyosthenia (eg, strength of hand grip $<30 \mathrm{~kg}$ in men and $<20 \mathrm{~kg}$ in women), exhaustibility (subjectively described by the patient), reduced walking velocity (less than $<0.8 \mathrm{~m} / \mathrm{s}$ ) and reduced physical activity (evaluated by history taking).

\section{Nutrition}

Malnutrition of elderly patients is frequently underestimated. For example, malnutrition was present in nearly $30 \%$ of the admitted patients in German hospitals. ${ }^{40}$ It is estimated that malnutrition-associated costs are nearly equal to obesityassociated costs. Sixty percent of the residents of nursing homes are estimated or diagnosed to be malnourished with the consequences of weight loss, enhanced sarcopenia, loss of muscle strength, diminished protein synthesis, and consequently increased mortality and morbidity. It is important to recognize that malnutrition can be masked by sarcopenic obesity. ${ }^{41}$ The causes of malnutrition are mostly multifactorial. Frequent factors are anorexia of elderly patients, gastrointestinal disorders, age-related diseases with cachexia (pulmonary, cardiac, nephrogenic, tumor cachexia), dementia and depression, addiction disorders and iatrogenic factors such as chemo- and radiotherapy, adverse effects of drugs, 
and prolonged fasting phases in hospitals. For the neurohospitalist, swallowing disorders and dysphagia are extremely important to recognize. ${ }^{42}$ This aspect has to be addressed in the diagnostic process by history taking and clinical examination. Crucial questions should therefore ask about weight loss (more than $5 \%$ of the body weight in a month or more than $10 \%$ in 6 months), appetite, and the current body weight. The body mass index (BMI) has to be determined, whereby a BMI of less than 20 to $22 \mathrm{~kg} / \mathrm{m}^{2}$ is considered to be pathological. Measuring the circumference of the calf (critical value $<31$ $\mathrm{cm}$ ) and the upper arm (critical value $21 \mathrm{~cm}$ ) are helpful parameters to estimate whole body muscle mass. ${ }^{43}$ Serum albumin, vitamin $\mathrm{B}_{12}$, folate acid, iron, and vitamin $\mathrm{D}$ are complementary surrogate markers. The Mini Nutrition Assessment test can easily be used as a questionnaire to assess the nutritional status at a glance. ${ }^{43}$

Nutrition plays an important role in the therapeutic process. As a rule, $50 \%$ of the energy of the meal should be covered by carbohydrates, $25 \%$ to $30 \%$ by fat, and $15 \%$ to $20 \%$ by proteins, whereby $1.2 \mathrm{~g}$ proteins per kilogram body weight should be ingested per day. Rapidly absorbed proteins such as contained in whey and proteins rich in leucine and other essential amino acids are advantageous. The average energy sum should constitute at least $30 \mathrm{kcal} / \mathrm{kg}$ of the body weight and the fluid intake $30 \mathrm{~mL} / \mathrm{kg}$ of the body weight. ${ }^{43}$

Aspiration pneumonia caused by swallowing disorders remains a big problem in elderly patients. It is therefore of crucial importance to screen the patient for swallowing dysfunction with bedside tests such as the water swallow test. A detailed examination including a fiber endoscopic evaluation of swallowing is mandatory in cases of abnormal screening tests. Individualized exercising, compensating, and adaptive measurements can be then applied to improve the patient's swallowing capacity. ${ }^{42}$ Drink supplements may also be used to improve nutrition. In addition, dental treatment measures should be considered to enhance the patient's chewing and taste capacity. ${ }^{44,45}$

A number of changes in water and electrolyte balance occur in old age such as reduction in total water, adipsia, and reduced kidney function and may represent an underlying cause for further disorders. Most frequently, hyponatremic dehydration arises manifesting itself with confusion, adynamia, constipation, falls, orthostatic hypotension, and renal failure. Measuring serum osmolarity, sodium, other osmotic substances, and analysis of urine sodium are helpful to differentiate the type of water imbalance. These results are essential to guide the therapy. 46

\section{Delirium}

The term delirium is used to describe an acute severe cerebral dysfunction with sudden onset and fluctuating signs and symptoms, whereby inattention, disorganized thinking, and impairment of consciousness are most frequently encountered. $^{47}$ The sleep-wake cycle is frequently disturbed. Both diminished and elevated psychomotor function as well as hyperactivity may be observed. Vegetative signs such as elevated body temperature, increased heart activity, and blood pressure frequently accompany the condition. Hypoactive, hyperactive, and mixed forms of delirium can be differentiated by clinical evaluation. Prevalence of delirium in elderly patients is high, and it is critical to diagnose hypoactive forms that are often not detected, as the patient is rather reticent and introverted. $^{48-50}$

Pathophysiologically, a cholinergic deficit combined with dopaminergic hyperactivity may be the final common pathway in delirious states. ${ }^{48}$ Many predisposing diseases (dementia, stroke, injuries) as well as many triggers are known such as polypharmacy, infection, pain, anesthesia, surgery, disorders of water and salt balance, or urine retention. ${ }^{49,50}$ It is of great importance to recognize these conditions and other risk factors in order to prevent delirium and to treat it as early as possible. Therapeutically, nonpharmacologic interventions are regulation of the environment and night-day rhythm, aids for orientation, concept of primary nursing, early mobilization, eyewear and hearing aids, and optimal hydration. However, occasional cases necessitate pharmacological therapy when patients are a danger to themselves or others. These patients are most commonly treated with neuroleptic drugs, which should generally be used in low dosages and only for a short period preferentially using newer ones with as little parkinsonian side effects as possible. ${ }^{48}$ It is always imperative to diagnose and to treat specific causes such as Wernicke encephalopathy, psychogenic agitation, withdrawal delirium, or nonconvulsive epileptic status.

\section{Pain in Elderly Patients and Palliative Medicine}

Pain in elderly patients is frequently encountered but still underreported. It is estimated that up to $53 \%$ of the elderly patients have chronic or relapsing pain. Pain is mostly related to chronic degenerative disorders of the musculoskeletal system, osteoporosis, rheumatic disorders, tumor, and neuropathic pain, the latter one predominantly due to zoster or polyneuropathy. ${ }^{51}$ It is of great importance to ask for pain during the clinical examination. ${ }^{13}$ It is necessary to record the location, type, intensity, and duration of the pain and its concomitant symptoms. The pain should be measured and monitored, for example, by using pain scales, such as visual analogue, numeric or verbal scale, or using pain face cartoons. Several tools for behavioral pain assessment have been developed for demented or nonverbal patients. ${ }^{51}$

Pain treatment is often challenging due to complex comorbidity and polypharmacotherapy. Nonpharmacological therapeutic methods such as thermal procedures, massage, kinesiatrics, lymphatic drainage, and medicinal bath, therapeutic application of local anesthetics, transcutaneous electrical stimulation, and occupational therapy play an important role. A great advantage of all these procedures is the attention 
of and close contact by the therapist. Nonsteroidal antiphlogistic drugs and opioids should be prescribed with caution due to their anticholinergic, serotonergic, and deliriogenic components. They are also known to promote a number of other critical unwanted side effects. As a rule, medication against pain should be given in low and slowly increasing dosages as well as "by the mouth" and "by the clock."

Palliative care and geriatrics share many concepts and principles. ${ }^{52}$ Curative and palliative measures are often necessary in combination in order to improve quality of life and the patient's individual situation. The patient's expectations and the medical evidence have to be balanced carefully. ${ }^{53}$ In palliative care, it is very helpful to apply measures to handle agonizing symptoms such as severe pain, confusion, agitation, exsiccation, dyspnea, nausea, and sleeplessness. Not only medical but also psychological, social, cultural, and spiritual needs of the seriously ill and dying person should be recognized and followed. As a rule, calendaric age should not be used as a prognostic tool in the treatment of elderly patients with cancer. The geriatric assessment is extraordinarily important to judge the functional status of the patient and to guide the therapy. The recently presented recommendations of the American Academy of Hospice und Palliative Medicine are thought-provoking as they recommend omitting the insertion of a percutaneous enteral gastrostomy in severely demented patients, to start early palliative care, to deactivate implanted cardioverter device, and to limit the therapy of an isolated bone metastasis to a single radiation. ${ }^{54}$

Advanced care planning is a dialogue with the patient to hear about his preferences and ideas of care, in particular when deterioration of his physical and/or mental status may occur. This dialogue includes the medical evidence, prognosis, options of palliative care, and contact to health-care providers and his relatives. All efforts should always have the aim to optimally address the patient's desires, values, spiritual needs, and preferences. ${ }^{55}$

\section{Ethics in Geriatrics}

The starting point of ethical thoughts is the human dignity as it is expressed in different historical human rights declarations (1776 Rights of Virginia, 1789 French Revolution, 1948 Declaration of Human Rights of the United Nations). Human dignity is determined impartible and not annullable; it is not given by human authorities and cannot be subducted by them. ${ }^{56}$ In case of impairment of the decison-making ability of a patient, for example, due to dementia, coma, or aphasia, the presumed will of the affected patient has to be determined and a representative has to negotiate it. Thus, it can be ensured that for the old and frail person, who is restricted in his capacity to decide, elementary needs are fulfilled. These elementary needs comprise basic medical care, keeping a private sphere, ban of exploitation, protection, and safety. ${ }^{56}$ In simpler words, "Human dignity is the right, not to be humiliated." 57 This means, medical professional measures always have to consider the human dignity of the patient. Therefore, in daily clinical care procedures, 3 rules have to be followed: (1) the medical indication must be given, (2) the confirmed consent by the patient or his representative (the patient's autonomy and/or will) has to be obtained, and (3) the medical measure has to be performed correctly in accordance with the current state of medical art. However, caring for elderly patients and frail person can go along with a number of subtle ethical dilemmas. ${ }^{58}$ The caregivers or children are often not aware of the significance of the role reversal of the geriatric patient, in particular in financial affairs. In nursing homes, the privacy of the elderly patient is encumbered by the dependency on professional nursing. Moreover, moving from a day clinic into permanent nursing care is a critical personal situation that necessitates an eminent psychosocial adaptation. A frequent dilemma is the assessment of the patient's decisionmaking capacity regarding the management of his personal affairs, the informed consent of medical procedures, and even the participation in medical research projects. Finally, ethical questions are very often at the direct borderline between life and death: Should resuscitation be performed? Should invasive diagnostic and therapeutic methods be applied? Should artificial feeding, ventilation, or renal dialysis be undertaken? Even more simple questions can be challenging: Can the patient be transferred from the hospital to home? Should nursing home care be arranged? ${ }^{59}$

Hence, it is of crucial importance to corroborate the ethical decision-making process by plausible facts and not by ungrounded assumptions. This means to elaborate as exactly as possible the patient's diagnosis, prognosis, and treatment options by applying the current medical expertise. Different ethical principles (beneficence, nonmaleficence, autonomy, justice) have to be balanced. ${ }^{59}$ At the end, the ethical principle has to become apparent in the concrete situation. This ethical decision process can be simplified by 3 steps. The first step is to determine the status quo by asking, Where do we stand?" The second step is the "quo vadis" question, "Where do we wish to go?" In the third step, the question about the means, "How can we achieve the goals aimed at?" has to be answered. These considerations are of enormous significance at the end of life. This condition can be described illustratively as the "orchestration of the end of life." ${ }^{, 59}$ The focus must strongly be put on the individual needs of the patient. He is setting the melody of the "last hurrah." In this context, it is noteworthy that recently developed psychotherapeutic dignity therapy can be beneficial with regard to anxiety, depression, and even existential and psychosocial distress. ${ }^{60}$

Moreover, caring for elderly patients requires fundamental attitudes and positions about age in general. The humanistic concepts should always be kept in mind, as Aristoteles expressed, "as old age is to life, so is evening to day."

In the field of ethics, concerns about elder abuse and elder self-neglect have also to be addressed. Recognition of elder abuse can be difficult, and intervention needs a broad professional base including social work, law enforcement, and 
protective services. ${ }^{61}$ Elder self-neglect is more delicate as the borders of self-determination to self-neglect are not sharp. Creativity and pragmatism are therefore mandatory to come up with the manifold problems of self-neglect. ${ }^{62}$

\section{Historical Note and Future Directions}

In a historical view, geriatric medicine is a young medical specialization. The term was implemented by Ludwig Nascher, a physician from Vienna, at the beginning of the 20th century. The first geriatric department in Germany was established in 1967 in Hofgeismar, followed by a department in the Albertissen Hospital in Hamburg in the $80 \mathrm{~s} .{ }^{63}$ In developing countries, geriatric departments are hitherto sparsely incorporated into municipal or rural hospitals. Due to demographic changes in nearly all industrialized countries and the transitional changes in developing countries, the importance of hospital treatment of the elderly and frail patient will, however, increase despite of controversies and debates.

A priori, geriatric medicine favors an approach that focuses on the preservation and restitution of function as it is relevant for the patients' daily activities. Pathophysiological considerations and evidence-based and organ-related medicine often play a secondary role due to the complexity of the individual patient's findings. This implies an individualized approach, which challenges the creativity of the multiprofessional caring team. However, this also leads to the critical concern that geriatric medicine frequently lacks evidence-based diagnostic and therapeutic concepts. Indeed, many of the applied clinical measures in geriatric medicine are not evaluated by randomized studies, although some studies demonstrated a significant benefit for a geriatric treatment concept. Nevertheless, this point of criticism will be strongly tackled in the future by the enhancement of evidence-based medicine in geriatrics. ${ }^{64-66}$

It is important for the general neurologist to turn toward the diagnostic and therapeutic processes important for the old and very old patients; every medical specialization needs geriatric competence. This approach has already been implemented successfully in some specialties, for example, in geriatric traumatology, neurogeriatrics, geriatric oncology, and others. The establishment of dementia wards with specific equipment and trained nurses to care for differently diseased dementia patients by a multiprofessional and interdisciplinary approach is another promising concept. ${ }^{67}$

As the demand of geriatric care is still growing, the number of physicians with geriatric competence has to increase accordingly. ${ }^{68}$ However, postgraduate training in geriatric medicine and even the field of geriatrics during regular medical training is still lacking in most medical universities. A type of gerontophobia has been observed, comparable to neurophobia. ${ }^{69}$ Furthermore, medical students seem not to favor learning geriatric medicine intensively. ${ }^{70}$ Thus, combined efforts should be made to push the esteem of geriatric medicine, for instance, by specific neurogeriatric training courses accompanied by neuro-geronto-philosophical colloquiums that include theological, spiritual, or philosophical topics. ${ }^{71}$ A further approach could be the implementation and evaluation of progressive and exciting educational initiatives with regard to age and aging. ${ }^{72}$ The initiative "Choosing Wisely in Geriatrics" may also enhance the position of geriatric medicine and counteract over- and undercare of the geriatric patient. ${ }^{73,74}$ In addition, the gap between gerontology and geriatric medicine has to be resolved. Interconnecting gerontologic knowledge with geriatric medicine will increase eminently in future. Finally, each generation has to look for answers to the questions: "Age, what is it? What is normal? How would we like to age? How do we deal with the fourth age? How do we deal with near death?"

\section{Acknowledgment}

The authors thank Dr Antonia Kostaki-Hechtel (Department of Geriatric Medicine, Municipal Hospital Landshut, Germany) for her continued support in the field of clinical geriatric medicine and helpful comments regarding the manuscript.

\section{Declaration of Conflicting Interests}

The authors declared no potential conflicts of interest with respect to the research, authorship, and/or publication of this article.

\section{Funding}

The authors received no financial support for the research, authorship, and/or publication of this article.

\section{References}

1. Jopp DS, Boemer K, Rott C. Health and disease at age 100: findings from the Second Heidelberg Centenarian Study. Dtsch Arztebl Int. 2016;113(12):203-210.

2. Ostan R, Monti D, Gueresi P, Bussolotto M, Franceschi C, Baggio G. Gender, aging and longevity in humans: an update of an intriguing/neglected scenario paving the way to a genderspecific medicine. Clin Sci. 2016;130(19):1711-1725.

3. Fries JF, Bruce B, Chakravarty E. Compression of morbidity 1980-2011: a focused review of praradigms and progress. J Ageing Res. 2011;2011:261702.

4. Kolb GF, Weißbach L. Demographic change: changes in society and medicine and developmental trends in geriatrics [in German]. Urologe A. 2015;54(12):1701-1709.

5. Dorsey ER, George BP, Leff B, Willis AW. The coming crisis: obtaining care for the growing burden of neurodegenerative conditions. Neurology. 2013;80(21):1989-1996.

6. Inouye SK, Studensky S, Tinetti ME, Kuchel GA. Geriatric syndromes: clinical research and policy implications of a core geriatric concept. J Am Geriatr Soc. 2007;55(5):780-791.

7. Van den Busche H, Schäfer I, Koller D, , et al. Multimorbidity in the German elderly population - part 1: prevalence in ambulatory medical care [in German]. Z Allg Med. 2012;88(9):365-371.

8. Heckmann JG, Duran JC, Galeoto J. The incidence of neurological disorders in tropical South America. Experience in the Bolivian lowlands [in German]. Fortschr Neurol Psychiatr. 1997;65(7):291-296. 
9. Crome P, Lally F. Frailty: joining the giants. CMAJ. 2011; 183(8):889-890.

10. Elsawy B, Higgins KE. The geriatric assessment. Am Fam Physician. 2011;83(1):48-56.

11. Ellis G, Whitehead MA, Robinson D, ÒNeill D, Langhorne P. Comprehensive geriatric assessment for older adults admitted to hospital: a meta-analysis of randomised controlled trials. $B M J$. 2011;343:d6553.

12. Blundell A, Gordon A, eds. Geriatric Medicine at a Glance. Sussex, UK: Wiley Blackwell; 2015.

13. Lachs MS, Feinstein AR, Cooney LM Jr, et al. A simple procedure for general screening for functional disability in elderly patients. Ann Intern Med. 1990;112(9):699-706.

14. Ärztliche Arbeitsgemeinschaft zur Förderung der Geriatrie in Bayern (AFGiB). Geriatrisches Screening bei Klinikaufnahme, Bayerisches Fachprogramm Akutgeriatrie, AFGiB 2011. http:// afgib.de. Accessed November 1, 2017.

15. McCusker J, Bellavance F, Cardin S, Trepanier S. Screening for geriatric problems in the emergency department: reliability and validity. Identification of Seniors At Risk (ISAR) Steering Committee. Acad Emerg Med. 1998;5(9):883-893.

16. Neubart R (Hrsg.). Repetitorium Geriatrie [in German]. Berlin, Heidelberg: Springer-Verlag; 2015.

17. Rennke S, Ranji SR. Transitional care strategies from hospital to home: a review for the neurohospitalist. Neurohospitalist. 2015; 5(1):35-42.

18. Kolb G, Breuninger K, Gronemeyer S, et al. Ten years of early complex geriatric rehabilitation therapy in the DRG system [in German]. Z Gerontol Geriatr. 2014;47(1):6-12.

19. Kwetkat A, Lehmann T, Wittrich A. Early geriatric rehabilitation. An opportunity for the oldest old [in German]. Z Gerontol Geriatr. 2014;47(5):372-378.

20. von Renteln-Kruse W, Anders J, Dapp U. Rehabilitation instead of nursing care. Current state and future demand of geriatric rehabilitation [in German]. Bundesgesundheitsblatt Gesundheitsforschung Gesundheitsschutz. 2011;54(4): 489-495.

21. Dormann H, Sonst A, Müller F, et al. Adverse drug events in older patients admitted as an emergency. The Role of Potentially Inappropriate Medication in Elderly People (PRISCUS). Dtsch Ärztebl Int. 2013;110(13):213-219.

22. Hanke F, Plum M, Wiedemann A. Geriatric pharmacotherapy in urology: an introduction from a geriatric pharmacist's perspective [in German]. Aktuelle Urol. 2016;47(1):65-73.

23. Wallace J, Paauw DS. Appropriate prescribing and important drug interactions in older adults. Med Clin North Am. 2015; 99(2):295-310.

24. Moßhammer D, Haumann H, Mörike K, Joos S. Polypharmacy - an upward trend with unpredictable effects. Dtsch Arztebl Int. 2016;113(38):627-33.

25. Parekh N, Page A, Ali K, Davies K, Rajkumar C. A practical approach to the pharmacological management of hypertension in older people. Ther Adv Drug Saf. 2017;8(4):117-132.

26. Drenth-van Maanen AC, van Marum RJ, Knol W, van der Linden CM, Jansen PA. Prescribing optimization method for improving prescribing in elderly patients receiving polypharmacy. Drugs Aging. 2009;26(8):687-701.

27. Frank C, Weir E. Deprescribing for older patients. CMAJ. 2014; 186(18):1369-1376.

28. Lavan AH, Galagher PF, ÒMahony D. Methods to reduce prescribing errors in elderly patients with multimorbidity. Clin Interv Aging. 2016;11:857-866.

29. Kwetkat A, Denkinger M, Bahrmann A, et al. Polypharmacy in the elderly [in German]. eCur Geriatr-module 4. Berlin, Heidelberg: Springer-Verlag; 2014.

30. Bramlage P, Siepmann M, Kirch W. Drug interactions in the elderly [in German]. Dtsch Med Wochenschr. 2004;129(16): 895-900.

31. Wooten JM. Rules for improving pharmacotherapy in older adult patients: part 1 (rules 1-5). South Med J. 2015;108(2):97-104.

32. Wooten JM. Rules for improving pharmacotherapy in older adult patients: part 2 (rules 6-10). South Med J. 2015;108(3):145-150.

33. Mooijaart SP, Broekhuizen K, Trompet S, et al. Evidence-based medicine in the older patients: how can we do better? Neth J Med. 2015;73(5):211-218.

34. Benzinger P, Rapp K, Becker C, et al. Mobility, immobility and risk of falling in old age. [in German] eCur Geriat-module 1. Berlin, Heidelberg: Springer-Verlag; 2014.

35. Tinetti ME. Preventing falls in elderly persons. $N$ Engl J Med. 2003;348(1):42-49.

36. Phelan EA, Mahoney JE, Voit JC, Stevens JA. Assessment and management of fall risk in primary care settings. Med Clin North Am. 2015;99(2):281-293.

37. Cumbler EU, Simpson JR, Rosenthal LD, Likosky DJ. Inpatient falls - defining the problem and identifying possible solutions. Part I: an evidence-based review. Neurohospitalist. 2013;3(3): 135-143.

38. Sieber CC.Sarcopenia [in German]. Ther Umsch. 2014;71(3): 171-176.

39. Lee L, Heckman G, Molnar FJ. Frailty_identifying elderly patients at high risk of poor outcomes. Can Fam Physician. 2015;61(3):227-231.

40. Pirlich M, Schütz T, Norman K., et al. The German hospital malnutrition study. Clin Nutr. 2006;25(4):563-572.

41. Drey M, Kaiser MJ. Malnutrition in the elderly [in German]. Dtsch Med Wochenschr. 2011;136(5):176-78.

42. Wirth R, Dziewas R, Beck AM, et al. Oropharyngeal dysphagia in older persons - from pathophysiology to adequate intervention: a review and summary of an international expert meeting. Clin Interv Aging. 2016;11:189-208.

43. Diekmann R, Kaiser M, Modreker M, et al. Geriatrics. Nutrition in the elderly. [in German] eCur Geriat - module 5. Berlin, Heidelberg: Springer-Verlag; 2014:1-42.

44. Heckmann SM, Heckmann JG, Weber HP. Clinical outcomes of three Parkinson's disease patients treated with mandibular implant overdentures. Clin Oral Implants Res. 2000;11(6): 566-571.

45. Heckmann SM, Hujoel P, Habiger S, et al. Zinc gluconate in the treatment of dysgeusia - a randomized clinical trial. J Dent Res. 2005;84(1):35-8. 
46. Al-Salman J, Kemp D, Randall D. Hyponatremia. West J Med. 2002;176(3):173-176.

47. Kostas TRM, Zimmerman KM, Rudolph JL. Improving delirium care - prevention, monitoring, and assessment. Neurohospitalist. 2013;3(4):194-201.

48. Lorenzl S, Füsgen I, Noachtar S. Acute confusional state in the elderly-diagnosis and treatment. Dtsch Ärztebl Int. 2012; 109(21):391-400.

49. Kalish VB, Gillham JE, Unwin BK. Delirium in older persons: evaluation and management. Am Fam Physician. 2014:90(12): 150-158.

50. Inouye SK, Westendorp RG, Saczynski JS. Delirium in elderly people. Lancet. 2014;383(9920):911-922.

51. Reid MC, Eccleston C, Pillemer K. Management of chronic pain in older adults. BMJ. 2015;350:h532.

52. Kunz R.Palliative care and geriatrics - similarities and opposites [in German]. Ther Umsch. 2012;69(2):115-119.

53. Calman KC. Quality of life in cancer patients - a hypothesis. $J$ Med Ethics. 1984;10(3):124-127.

54. Fischberg D, Bull J, Casarett D, et al. Five things physicians and patients should question in hospice and palliative medicine. $J$ Pain Symptom Manage. 2013;45(3):595-605.

55. Glaudemans JJ, Moll van Charante EP, Willems DL. Advance care planning in primary care, only for severely ill patients? A structured review. Fam Pract. 2015;32(1):16-26.

56. Bachmeier H. Lektionen des Alters. Göttingen, Germany: Wallstein-Verlag; 2015.

57. Bjeri P. Über die Vielfalt menschlicher Würde. München, Germany: Hansa-Verlag; 2013.

58. Rosin AJ, van Dijk Y. Subtle ethical dilemmas in geriatric management and clinical research. J Med Ethics. 2005;31(6): 355-359.

59. Frühwald T. Ethics in geriatrics [in German]. Z Gerontol Geriatr 2012;45:545-557.

60. Martinez M, Arantzamendi M, Belar A, et al. 'Dignity therapy', a promising intervention in palliative care: a comprehensive systematic literature review. Palliat Med. 2017;3(6):492-509.

61. Lachs MS, Pillemer KA. Elder abuse. New Engl J Med. 2015; 373(20):1947-1956.

62. Smith AK, Lo B, Aronson L. Elder self-neglect-how can a physician help? New Engl J Med. 2013:369(26):2476-2479.

63. Nau R, Djukic M, Wappler M. Geriatrics - an interdisciplinary challenge [in German]. Nervenarzt. 2016;87(6):603-608.

64. Frühwald T. Wise therapeutic decisions for older patients. Wien Med Wochenschr. 2016;166(5-6):147-148.
65. Libman H, Melin JA, Sullivan DJ, et al. What's new in geriatrics. https://www.uptodate.com. Assessed November 2, 2017.

66. Messinger-Rapport BJ, Factora N. Geriatrics update 2015: vaccination, frailty, chronic disease guidelines, and cognition. Cleve Clin J Med. 2015;82(8):498-505.

67. von Renteln-Kruse W, Neumann L, Klugmann B, et al. Geriatric patients with cognitive impairment-patient characteristics and treatment results on a specialized ward. Dtsch Ärztebl Int. 2015; 112(7):103-112.

68. Sieber CC. The elderly patient-who is that? [in German]. Internist (Berl). 2007;48(11):1190-1194.

69. Mulder JD.Gerontophobia and medical education [in Dutch]. Tijdschr Gerontol Geriatr. 1984;15(6):227-229.

70. Meiboom AA, de Vries H, Hertogh C, Scheele F. Why medical students do not choose a career in geriatrics: a systematic review. BMC Med Educ. 2015;15:101

71. Leget $\mathrm{C}$. Why good quality care needs philosophy more than compassion. Int J Health Policy Manag. 2015;4(10):677-679.

72. Kazar MW. Responding to the silver tsunami with progressive and exciting educational initiatives. Nurs Educ Perspect. 2012; 33(3): 143 .

73. AGS Choosing Wisely Workgroup. American Geriatrics Society identifies five things that healthcare providers and patients should question. J Am Geriatr Soc. 2013;61(4):622-631.

74. AGS Choosing Wisely Workgroup. American Geriatrics Society identifies another five things that healthcare providers and patients should question. J Am Geriatr Soc. 2014;62(5): 950-960.

75. Schott JM. The neurology of ageing: what is normal? Pract Neurol. 2017;17(3):172-182.

76. Nikolaus T, Bach M, Specht-Leible N, Oster P, Schlierf G. The timed test of money counting: a short physical performance test for manual dexterity and cognitive capacity. Age Ageing. 1995; 24(3):257-258.

77. Nikolaus T, Specht-Leible N, Bach M, Oster P, Schlierf G. Social aspects in diagnosis and therapy of very elderly patients. Initial experiences with a newly developed questionnaire within the scope of geriatric assessment [in German]. Z Gerontol. 1994; 27(4):240-245.

78. Warden V, Hurley AC Volicer L. Development and Psychometric Evaluation of the Pain Assessment in Advanced Dementia (PAINAD) Scale. J Am Med Dir Assoc. 2003;4(1):9-15.

79. Holen JC, Saltvedt I, Fayers PM, Hjermstad MJ, Loge JH, Kaasa S. Doloplus-2, a valid tool for behavioural pain assessment? BMC Geriatr. 2007;7:29. 